\title{
PREVISIBILIDADE DE UM VENDAVAL COM TORNADO OCORRIDO EM CANGUÇU COM O MODELO WRF-ARW
}

\author{
Luciana Cardoso Neta ${ }^{1}$, Eliton Lima de Figueiredo ${ }^{2}$, \\ Vladair Morales de Oliveira ${ }^{2}$, Eliane Grala Pereira Alves ${ }^{2}$, Roseli Gueths Gomes ${ }^{2}$ \\ ${ }^{1}$ Universidade Federal de Santa Maria - UFSM \\ Pós-Graduação em Meteorologia \\ Campus Universitário, Santa Maria, RS. \\ lcneta@gmail.com \\ ${ }^{2}$ Universidade Federal de Pelotas - UFPel \\ Centro de Pesquisas e Previsões Meteorológicas \\ Av. Ildefonso Simões Lopes, 2751, 96060-290, Pelotas, RS. \\ elitonlf@gmail.com, vladair.oliveira@gmail.com, eliane.grala@gmail.com,rggomes@ufpel.edu.br
}

RESUMO: Neste trabalho, será analisado o vendaval com formação tornádica, ocorrido em Canguçu/RS em maio de 2013, com dados observacionais e provenientes de simulações atmosféricas. O modelo WRF-ARW com resolução horizontal de $2 \mathrm{~km}$ forneceu intensidades dos ventos a $2 \mathrm{~m}$ compatíveis aos observados, o que permite especular sobre a previsibilidade de ventos fortes no estado.

PALAVRAS-CHAVE: modelagem atmosférica, ventos fortes

ABSTRACT: This work analyses the windstorm, with tornadic formation, occurred on Canguçu/RS in May 2013, with data from observational and atmospheric simulations. The WRF-ARW model with horizontal resolution of $2 \mathrm{~km}$ provided the intensity of the wind $2 \mathrm{~m}$ compatible to those observed, allowing to speculate about the predictability of strong winds in the state.

KEYWORDS: atmospheric modeling, strong winds

\section{INTRODUÇÃO}

A previsão de eventos meteorológicos severos é, hoje, um desafio constante nos Centros Operacionais de Previsão do Tempo, a nível mundial. Isto se deve às perdas materiais e, 
principalmente, à de vidas humanas. O tornado é o fenômeno meteorológico mais destrutivo que ocorre na atmosfera, à escala local e, por isto, a sua previsão é de vital importância. O objetivo deste trabalho é avaliar a previsibilidade da magnitude dos ventos, a $2 \mathrm{~m}$ de altura, gerados pelo modelo WRF-ARW para um evento de ventos fortes, ocorrido em Canguçu/RS, no mês de maio de 2013. De acordo com os estragos causados (DEFESA CIVIL, 2013), este evento apresentou características de um tornado F2 segundo a classificação de Fujita (1981).

\section{MATERIAIS E MÉTODOS}

A situação sinótica foi avaliada com imagens de satélite geoestacionário, obtidas junto ao CPTEC/INPE. Foram também utilizados os dados de refletividade, do radar meteorológico (DECEA), e de ventos, da estação automática (INMET), ambos localizados na região central de Canguçu.

Os campos de vento do modelo global GFS (resolução de $0,5^{\circ}$ a cada 3 horas) foram comparados com aqueles obtidos com o modelo de mesoescala WRF-ARW. Este último foi configurado para 3 grades aninhadas (resoluções de $18 \mathrm{~km}, 6 \mathrm{~km}$ e $2 \mathrm{~km}$, respectivamente) e saídas horárias. As simulações para 24 horas de processamento, tiveram início à 0:00UTC do dia 3 de maio de 2013, com dados iniciais da análise e, a cada 3 horas, dados da previsão do modelo global GFS.

\section{RESULTADOS E DISCUSSÃO}

A Fig. 1a mostra a nebulosidade de uma frente fria sobre o estado do Rio Grande do Sul, no horário de maior magnitude das rajadas de vento observadas na estação automática. Os valores atingiram $27,8 \mathrm{~m} / \mathrm{s}$, o que equivale a cerca de $100 \mathrm{~km} / \mathrm{h}$. Nesta figura, o círculo indica a área de alcance de $200 \mathrm{~km}$ de raio, a partir do radar. Compreendida nesta área, os maiores valores de refletividade, superiores a $35 \mathrm{dBZ}$, (Fig. 1b) estão localizados ao norte do radar, onde ocorreram os maiores danos. Valores de refletividade a partir de $40 \mathrm{dBZ}$ indicam a existência de convecção profunda (COTTON; ANTHES, 1989). 
(a)

20:00UTC
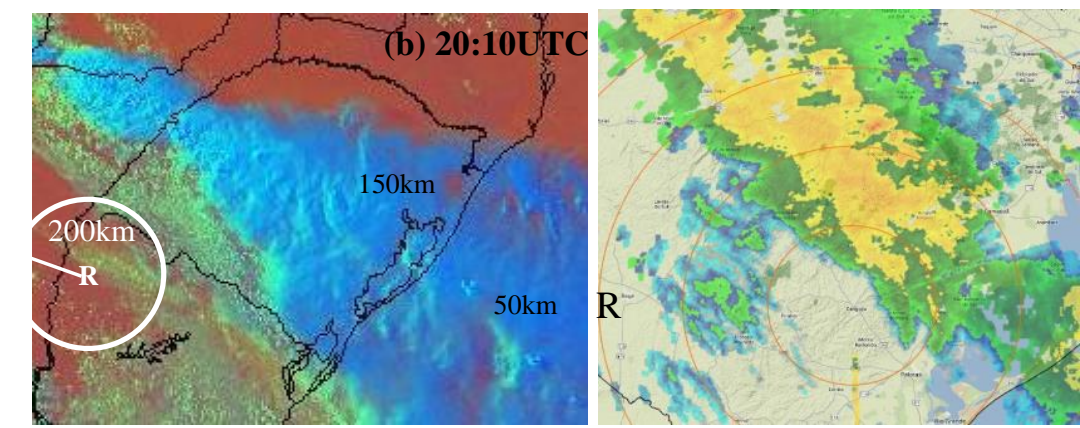

Figura 1 - Segmentos das imagens (a) de satélite, (b) do radar de Canguçu, no dia 03/05/2013 e horários indicados. $(\mathrm{R}=$ radar $)$

Na Fig. 2, são mostrados os resultados fornecidos pelos modelos GFS (Fig. 2a, 2b) e WRFARW (Fig. 2c). O quadrado (em vermelho) nas Fig. 2a, 2b indicam a área do domínio $2 \mathrm{~km}$ de restituição com o modelo WRF, mostrado na Fig. 2c. O modelo GFS não conseguiu identificar áreas com ventos fortes nas proximidades de Canguçu. Por outro lado, o modelo WRF-ARW forneceu valores elevados de vento bem próximos aos observados na estação automática de Canguçu (destacada pelo círculo, na Fig. 2c). Ao norte desta, onde ocorreram os estragos, os valores foram ainda maiores, entre 20 e $25 \mathrm{~m} / \mathrm{s}$.
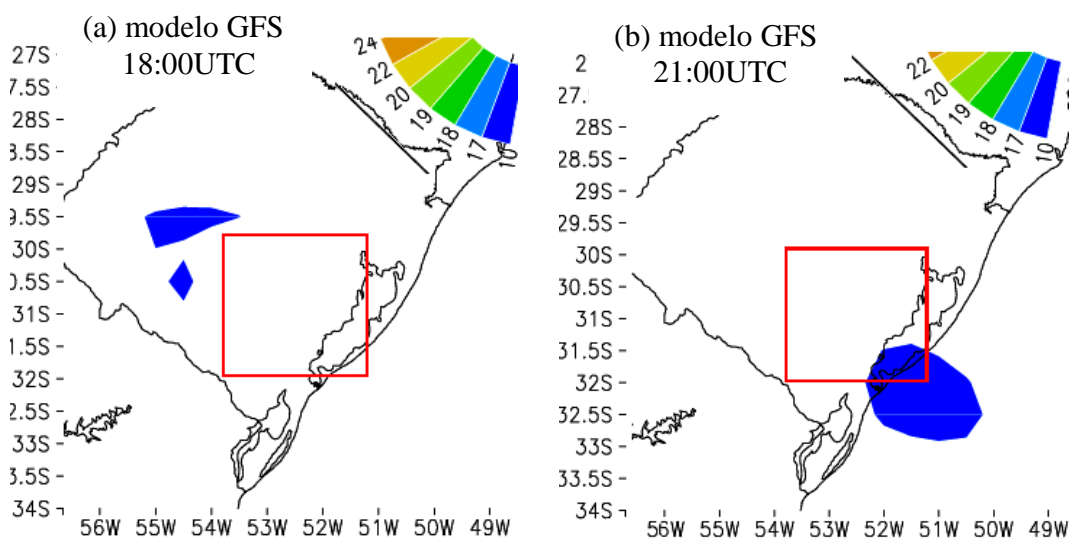

Figura 2 - Magnitude do vento a $2 \mathrm{~m}$, obtidos com os modelos (a) GFS às 18:00UTC, (b) GFS às 21:00UTC, (c) WRF-ARW às 20:00UTC. Os quadrados (em vermelho) nas figuras a e b indicam a localização do campo mostrado na figura c. 


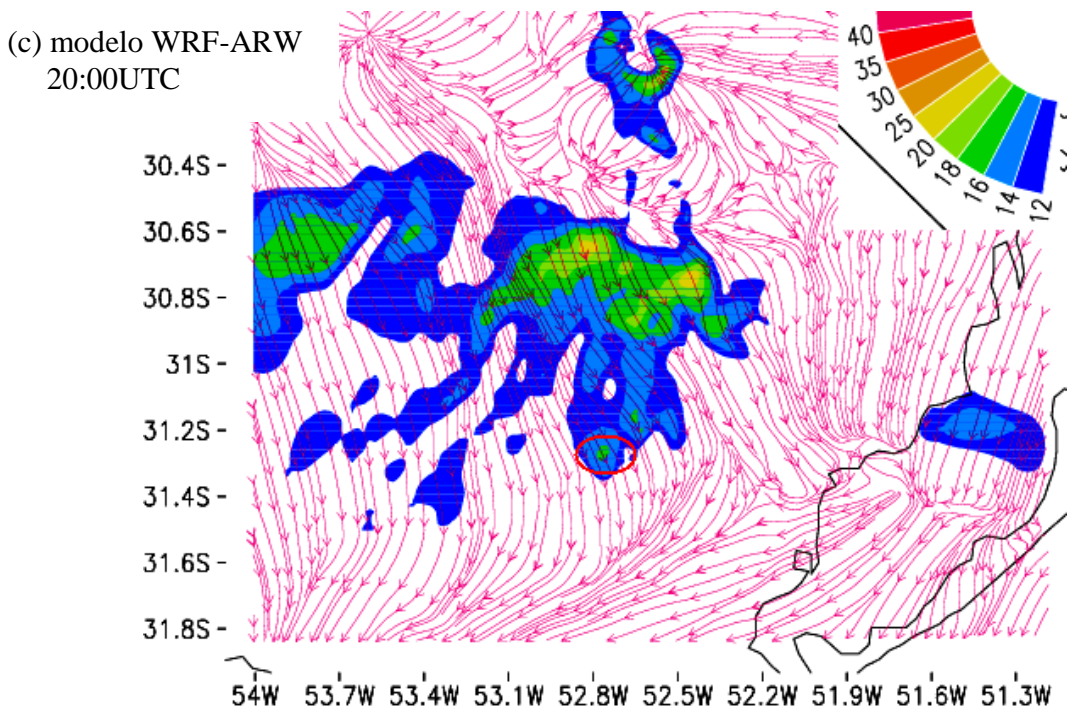

Figura 2 - Continuação.

\section{CONCLUSÕES}

b)

Para um evento de vendaval com formação tornádica, ocorrido em Canguçu/RS, foi mostrado que com alta resolução espacial e resolução temporal de uma hora, o modelo WRF-ARW conseguiu restituir os elevados valores de vento, próximos aos observados na estação automática. Este resultado indica a possibilidade de previsão de ventos fortes, utilizando modelagem atmosférica nos Centros de Operacionais de Previsão do Tempo.

\section{REFERÊNCIAS}

COTTON, W. R.; ANTHES, R. A. Storm and Cloud Dynamics. Academic Press, San Diego,

Califórnia, 1989, 884p.

DEFESA CIVIL. Disponível em: <http://www.defesacivil.rs.gov.br/>. Acesso em: 20 de ago. 2013.

FUJITA, T.T. Tornadoes and Downbursts in the Context of Generalized Planetary Scales. Journal of the Atmospheric Sciences, v. 38, n.8, p.1511-1534, 1981. 